\title{
Demographic and clinical variables as differentiating predictors of cognitive disorders in Parkinson's disease
}

Núbia Isabela Macêdo Martins' (ID Nadja Maria Jorge Asano² Carla Cabral dos Santos Accioly Lins ${ }^{3}$ ID Maria das Graças Wanderley de Sales Coriolano ${ }^{3}$ (D)

\section{Abstract}

Objective: to analyze demographic and clinical variables as predictors of cognitive disorders in Parkinson's disease (PD). Method: a cross-sectional descriptive study was carried out at the Pro-Parkinson Program of the Hospital das Clínicas of the Federal University of Pernambuco. The instruments used were the Mini Mental State Examination (MMSE), Scales for Outcomes in Parkinson's disease - Cognition (SCOPA-COG), the Hoehn \& Yahr Staging Scale (HY), the Unified Parkinson's Disease Rating Scale part 3 (UPDRSIII), and the 15-item Yesavage Geriatric Depression Scale (GDS-15). A multiple linear regression model was used for the predictive outcome and the Mann-Whitney test was used to compare the elderly and the non-elderly groups. Results: the sociodemographic data of 85 people were collected and the participants underwent a cognitive profile evaluation (MMSE and SCOPA-COG) and clinical evaluation (HY, UPDRS-III, GDS-15). Multiple regression analysis found significant results for age, work activity, and tremor index, explaining $59 \%$ of the variability of SCOPA-COG. There was an inverse correlation with age and work activity and a direct correlation with tremors. The SCOPA-COG and MEEM scores were significantly lower in elderly patients, with an emphasis on executive functions. Conclusion: the predictors of cognitive impairment were age, work activity, and tremors. Cognitive impairment was greater in elderly patients with PD, especially for executive functions.

\footnotetext{
Universidade Federal de Pernambuco, Centro de Ciências da Saúde, Departamento de Gerontologia, Programa de Pós-graduação em Gerontologia. Recife, Pernambuco, Brasil.

2 Universidade Federal de Pernambuco, Centro de Ciências da Saúde, Departamento de Medicina. Recife, Pernambuco, Brasil.

3 Universidade Federal de Pernambuco, Centro de Ciências da Saúde, Departamento de Anatomia. Recife, Pernambuco, Brasil.
} orrespondence

Keywords: Aging. Cognition. Parkinson Disease. 


\section{INTRODUCTION}

The aging process can be accompanied by the onset of chronic diseases and the complications that accompany them. Parkinson's Disease (PD) and Alzheimer's Disease are the most prevalent neurodegenerative diseases that affect elderly people ${ }^{1}$. PD is characterized by the degeneration of the dopaminergic neurons of the compact part of the substantia nigra of the midbrain. Its main motor signs and symptoms are bradykinesia, rigidity, resting tremors and postural instability ${ }^{2}$.

Individuals with PD also have a heterogeneity of cognitive deficits in their executive functions, language, memory and visuospatial ability, especially in older elderly persons with Parkinson's. This may be characterized by mild cognitive impairment (MCI) or even dementia ${ }^{3,4}$. Given this risk, early identification of the disease is necessary. Guidelines for the diagnosis of $\mathrm{MCI}$ and dementia in PD have already been proposed ${ }^{5,6}$, but there remains a lack of well-validated criteria for the diagnosis of cognitive deficits in elderly patients with $\mathrm{PD}^{7}$.

Advanced age, schooling, and clinical profile are some of the factors explored in studies of cognitive impairment in patients with $\mathrm{PD}^{8-11}$. However, the association between these variables and cognition, comparing groups of Brazilian elderly and nonelderly persons with $\mathrm{PD}$, has yet to be performed.

The objective of the present study was therefore to analyze demographic and clinical variables as differentiating predictors of cognitive disorders in individuals with Parkinson's disease.

\section{METHOD}

A descriptive-analytical cross-sectional study was performed at the Neurology Outpatient Clinic of the Hospital das Clínicas of the Universidade Federal de Pernambuco (HC/UFPE) between January and June 2017, in association with the activities of the Pro-Parkinson's Program. Patients with a clinical diagnosis of idiopathic Parkinson's disease and satisfactory communicative levels, who had no other neurological diseases, had not undergone surgical interventions in the brain and were not receiving cognitive rehabilitation treatment were selected to participate in the program. The criterion used for the definition of elderly was 60 years of age or older at the time of evaluation. The sample size needed to estimate the mean SCOPA-COG with an accuracy of 1.2 points based on a confidence interval of $95 \%$ was 76 patients.

The Scales for Outcomes in Parkinson's DiseaseCognition (SCOPA-COG) and Mini Mental State Examination (MMSE), both validated for use with the Brazilian population, were used as instruments to collect data to assess cognitive profile ${ }^{12,13}$.

The SCOPA-COG scale evaluates memory, attention, executive functions and visuospatial function, and was developed specifically for the evaluation of the cognitive domains in which patients with PD are frequently deficient ${ }^{14}$. The maximum score of 43 indicates better cognitive performance, while the cut-off point used to indicate dementia was $17^{15}$, and that for the indication of MCI was $26^{16}$.

The MMSE is the most widely used cognitive screening tool in Brazil and around the world, and was employed as a reference in this study. It assesses temporal and spatial orientation, short-term memory and recall, attention and calculation, and language and visuospatial skills ${ }^{17}$. The Brucki et al. ${ }^{18}$ version was used in the present study, with 18 the cutoff point for dementia for illiterate individuals, 21 the cutoff for people with 1 to 4 years of schooling, 24 for those with 5 to 8 years of schooling and 26 for those with more than 8 years of schooling. The maximum score of 30 points indicates better cognitive performance ${ }^{19}$.

A form was used to obtain the sociodemographic characteristics of the sample, with respect to age, gender, years of schooling, work activity, economic classification, comorbidities, and equivalent dose of L-dopa being used.

Work activity was divided into three categories G (1), G (2) and G (3), with group G (1) composed of professions with higher cognitive demands and G (3) those with lower demands. Professions in G1 included: science and arts professionals, managers, mid-level technicians; G2: administrative service 
workers, vendors and service providers, artisans and production workers, machine operators and assemblers, members of the armed forces; and G3: agricultural workers, housewives and manual workers.

Economic classification was defined according to the updated 2016 criterion of the Associação Brasileira de Empresas de Pesquisa (the Brazilian Association of Research Companies ${ }^{20}$, which defines socioeconomic strata based on the possession of goods, access to water, the state of the street where the home is located and educational level of the head of household. Each item receives a score, the sum of which varies from 1 to 100 and indicates the stratum to which the individual belongs. Stratum A corresponds to the highest average household income, while $\mathrm{B} 1$ and $\mathrm{B} 2, \mathrm{C} 1$ and $\mathrm{C} 2$, and $\mathrm{D}-\mathrm{E}$, sequentially represent lower mean household incomes.

The Hoehn \& Yahr Staging Scale (HY), the Unified Parkinson's Disease Scale, Part 3 (UPDRSIII) and the 15-item Yesavage Geriatric Depression Scale (GDS-15) were used to assess the clinical profile of patients, and the equivalent daily L-dopa dose (DLDD) was calculated.

DLDD was calculated according to the following formula: dose of (immediate release levodopa x 1) + (controlled release levodopa $\mathrm{x} 0.75)+($ pramipexole $\mathrm{x} 100)+($ entacapone $\mathrm{x} 0.33)+($ oral selegiline $\mathrm{x} 10)$ $+(\operatorname{amantadine} \mathrm{x} 1)^{21}$.

The HY scale was applied in the "off-medication" state to indicate the stage of PD of the subject (from 1 to 5). The higher the stage, the greater the severity of the disease.

UPDRS-III was used to assess the motor status of patients with PD. The score ranges from 0 to 108, with the higher the score, the worse the motor impairment. Tremor, Rigidity, Bradykinesia and Postural Instability Indices were obtained by adding their respective scores and dividing by the number of body regions evaluated in the UPDRS-III item ${ }^{22,23}$ :

- Tremor with two items and seven body regions: item 20 (face, lips and chin, right hand, left hand, right foot, left foot) and item 21 (right hand, left hand);
- Rigidity with one item and five body regions: item 22 (neck, upper right limb, upper left limb, lower right limb, lower left limb);

- Bradykinesia with five items and nine body regions: items 23,24,25 and 26 (right sides, left sides) added to the item 31 score;

- Postural Instability with four items: 27, 28, 29 and 30 .

The GDS-15 was used as a screening tool for depression with a total score of five or more points indicating suspected depression ${ }^{24}$. Subjects were invited to participate in the research in the waiting room of the outpatient clinic on the days of routine medical consultations. For data collection, the interview and evaluations were performed at the same time in a private room with patients in an on-medication stage.

The instruments were applied in the following order: 1. Sociodemographic Data Sheet; 2. SCOPACOG; 3. UPDRS-III; 4. MMSE; 5. GDS-15. The exception was the evaluation of the stage of the disease, using the Hoehn \& Yahr Scale. As this requires the patient to be in an off-medication state, in some cases it was necessary to schedule evaluation for the date of the next medical consultation. Data collection was performed by a researcher with previous experience in evaluation (cognitive, motor) of people with PD.

The Kolmogorov-Smirnov test was used to verify normality. Using a multiple linear regression, the independent predictor variables of the SCOPA-COG score were identified. The intergroup comparison (elderly vs. non-elderly) was performed using the Mann-Whitney test. To test association between age and cognitive status, the $\mathrm{X}^{2}$ test, odds ratio and 95\% Confidence Index were applied. The Statistica 13.2 software programme was used, with $p \leq 0.05$.

All the patients signed a Free and Informed Consent Form and the research was only carried out following approval from the Ethics Committee for Research Involving Human Beings of the Health Sciences Center of the Universidade Federal de Pernambuco under approval number 1814.749/2016, according to Resolution No. 466/2012 of the National Health Council. 


\section{RESULTS}

Table 1 displays the general characteristics (gender, age, economic classification, schooling and work activity) of the total sample and the elderly and non-elderly groups. In the total sample there was a higher percentage of male subjects, aged 60-69 years, from socioeconomic stratum $\mathrm{C}$, with two to five years of study and in labor activity group G2.

The multiple linear regression model found that the variables age, work activity and tremor index were significant, explaining $59 \%$ of variability in SCOPCOG (Table 2). Age and work activity exhibited an inverse correlation, while tremor displayed a direct correlation. The SCOPA-COG score decreased by 0.18 points for each one-year increase and five points for each change in group: from G1 (greater cognitive demand) to G2 or from G2 to G3 (lower cognitive demand). An increase of 10.2 points was observed for each increment of one point in the tremor index, which varies in a decimal form from 0 to 4 .

When the groups of elderly and non-elderly patients were compared, there was a significant difference only in terms of DLDD, MMSE and overall SCOPA-COG score and the Executive functions domain of the scale (Table 3). According to the SCOPA-COG cut-off points for MCI and dementia, the presence of cognitive impairment was higher in the elderly $(75 \%)$ than in the non-elderly $(59 \%)$ group. The elderly also had a higher percentage of cognitive impairment based on the MMSE cutoff points for dementia (36\%).

Table 1. General characteristics of sample (N=85), Recife, Pernambuco, 2017.

\begin{tabular}{|c|c|c|c|}
\hline Variables & $\begin{array}{l}\text { Total (85) } \\
\mathrm{n}(\%)\end{array}$ & $\begin{array}{l}\text { Elderly (53) } \\
\mathrm{n}(\%)\end{array}$ & $\begin{array}{l}\text { Non-Elderly (32) } \\
\mathrm{n}(\%)\end{array}$ \\
\hline \multicolumn{4}{|l|}{ Gender } \\
\hline Male & $47(55)$ & $28(53)$ & $19(59)$ \\
\hline Female & $38(45)$ & $25(47)$ & $13(41)$ \\
\hline \multicolumn{4}{|l|}{ Age } \\
\hline 30 to 39 years & $1(1)$ & $0(0)$ & $1(3)$ \\
\hline 40 to 49 years & $8(9)$ & $0(0)$ & $8(25)$ \\
\hline 50 to 59 years & $23(27)$ & $0(0)$ & $23(72)$ \\
\hline 60 to 69 years & $29(34)$ & $29(55)$ & $0(0)$ \\
\hline 70 to 79 years & $22(26)$ & $22(41)$ & $0(0)$ \\
\hline 80 years and over & $2(2)$ & $2(4)$ & $0(0)$ \\
\hline \multicolumn{4}{|c|}{ Economic Classification - ABEP } \\
\hline $\mathrm{B}$ & $26(31)$ & $16(30)$ & $10(31)$ \\
\hline W & $37(43)$ & $24(45)$ & $13(41)$ \\
\hline $\mathrm{D}$ & $22(26)$ & $13(25)$ & $9(28)$ \\
\hline \multicolumn{4}{|l|}{ Years of schooling } \\
\hline 2 to 5 years & $33(39)$ & $26(49)$ & $7(22)$ \\
\hline 6 to 9 years & $13(15)$ & $4(8)$ & $9(28)$ \\
\hline 10 to 12 years & $19(22)$ & $8(15)$ & $11(34)$ \\
\hline 13 and over & $20(24)$ & $15(28)$ & $5(16)$ \\
\hline \multicolumn{4}{|l|}{ Work activity } \\
\hline G1 & $22(26)$ & $16(30)$ & $6(19)$ \\
\hline G2 & $32(38)$ & $17(32)$ & $15(47)$ \\
\hline G3 & $31(36)$ & $20(38)$ & $11(34)$ \\
\hline
\end{tabular}

Note: ABEP= Associação Brasileira de Empresas de Pesquisa (Brazilian Association of Research Companies)

G1: group with work activity of greater cognitive demand; G2: group with work activity of intermediate cognitive demand; G3: group with work activity of lower cognitive demand. 
Table 2. Multiple linear regression with SCOPA-COG as a dependent variable. Recife, Pernambuco, 2017.

\begin{tabular}{lll}
\hline Independent variables & $\mathrm{B}$ & $p^{*}$ \\
\hline Age (years) & -0.181 & $<0.01^{*}$ \\
\hline Schooling (years) & 0.185 & 0.32 \\
\hline Work Activity (G1;G2;G3) & -5.04 & $<0.01^{*}$ \\
\hline UPDRS-III & -0.83 & 0.07 \\
\hline Rigidity & 4.11 & 0.11 \\
\hline Tremors & 10.26 & $<0.01^{*}$ \\
Bradykinesia & 8.45 & 0.07 \\
\hline Postural instability & 1.35 & 0.58 \\
\hline GDS-15 & -0.10 & 0.64 \\
\hline
\end{tabular}

Note: General regression results: R²: 0. 59; F: 11.79; $p:<0.0001^{*}$

B: Regression coefficient; G1: work activity of greater cognitive demand; G2: work activity of intermediate cognitive demand; G3: work activity of lower cognitive demand. UPDRS-III: Unified Parkinson's Disease Rating Scale, part 3; GDS-15: 15-item Yesavage Geriatric Depression Scale.

Table 3. Cognitive and clinical profile of sample. Recife, Pernambuco, 2017.

\begin{tabular}{|c|c|c|c|c|}
\hline Variables & Total $(n=85)$ & Elderly $(n=53)$ & Non-Elderly $(\mathrm{n}=32)$ & $p^{*}$ \\
\hline Duration of disease: $\overline{\mathrm{x}}( \pm)$, years & $7(3)$ & $7(4)$ & $7(3)$ & 0.92 \\
\hline DLDD: $\bar{x}( \pm), m g /$ day & $783(612)$ & $712(608)$ & $900(609)$ & 0.02 \\
\hline SCOPA-COG: $\bar{x}( \pm)$ & $20(8)$ & $19(8)$ & $22(6)$ & 0.05 \\
\hline Memory and learning & $7(4)$ & $6(4)$ & $8(3)$ & 0.07 \\
\hline Attention & $3(1)$ & $3(2)$ & $3(1)$ & 0.70 \\
\hline Executive Functions & $7(3)$ & $6(3)$ & $8(3)$ & 0.01 \\
\hline Visuospatial Function & $3(2)$ & $3(2)$ & $3(1)$ & 0.32 \\
\hline Patients without CI: \% & $31 \%$ & $25 \%$ & $41 \%$ & \\
\hline Patients with CI: \% & $69 \%$ & $75 \%$ & $59 \%$ & \\
\hline MMSE: $\bar{x}( \pm)$ & $24(4)$ & $24(4)$ & $26(3)$ & 0.04 \\
\hline Patients without CI: \% & $71 \%$ & $64 \%$ & $81 \%$ & \\
\hline Patients with CI: \% & $29 \%$ & $36 \%$ & $19 \%$ & \\
\hline UPDRS - III: $\overline{\mathrm{x}}( \pm)$ & $30(14)$ & $28(14)$ & $26(15)$ & 0.60 \\
\hline Tremors & $1(0.8)$ & $0.4(0.4)$ & $0.4(0.4)$ & 0.78 \\
\hline Rigidity & $0.4(0.4)$ & $1(1)$ & $1(1)$ & 0.93 \\
\hline Bradykinesia & $1.2(0.8)$ & $1.3(0.8)$ & $1.2(0.8)$ & 0.81 \\
\hline Postural instability & $1.3(0.7)$ & $1.4(0.7)$ & $1.2(0.8)$ & 0.11 \\
\hline GDS-15: $\bar{x}( \pm)$ & $5(3)$ & $4(3)$ & $5(3)$ & 0.18 \\
\hline
\end{tabular}

Note: *: $p$ (Elderly vs Non Elderly). (Mann-Whitney Test). $\overline{\mathrm{x}}( \pm)$ : Mean (standard deviation); \%: Percentage; DLDD: equivalent daily L-dopa dose; SCOPA-COG: Scales for Outcomes in Parkinson's disease-Cognition; CI: cognitive impairment; MMSE: Mini-Mental State Exam; UPDRS-III: Unified Parkinson's Disease Rating Scale, part 3; GDS-15: 15-Item Yesavage Geriatric Scale. 
According to the SCOPA-COG criteria, elderly individuals were three times more likely $(\mathrm{OR}=3.32$ $95 \% \mathrm{CI}=1.06-10.79)$ to be categorized with cognitive impairment than non-elderly individuals (X2 = 5.39 with $p=0.02$ ). In terms of MMSE, the chance of such a categorization was almost two and a half times greater $(\mathrm{OR}=2.42-95 \% \mathrm{CI}=0.76-7.94)$ among the elderly (X2=2.81 with $p=0.09)$.

\section{DISCUSSION}

Age, work activity and tremors were the only variables that significantly influenced the total SCOPA-COG score $(p \leq 0.05)$. Age and PD seem to interact and negatively influence cognitive performance, specifically executive functions ${ }^{8}$.

Regarding work activity, Bohnen et al. ${ }^{25}$ and Silveira and Portuguez ${ }^{26}$, corroborate the findings of the present study by indicating that involvement in mentally stimulating activities is associated with a better cognitive status among the elderly, including those with PD. The results of the present study indicated that there was an inverse correlation between work activity and SCOPA-COG score, or in other words the higher the category of the profession $\mathrm{G}(3)$, the lower the test score. This makes sense as G3 had the lowest cognitive demand, and the findings of Pool et al. ${ }^{27}$ suggest that the higher the cognitive requirements of a profession, the better the individual's cognitive performance.

The complexity of the professional occupation performed throughout life directly influences cognitive reserve ${ }^{28}$. In theory, cognitive reserve allows individuals to cope better with the consequences of a disease which affects cognitive abilities, and remain clinically healthy for longer ${ }^{29}$. No studies were found that associate the cognitive demand of an occupation with the incidence/prevalence of the diagnosis of dementia in PD.

The tremors variable, measured by UPDRS-III, correlated directly with total SCOPA-COG score. This result can be explained by a possible protective factor associated with tremor symptoms. Baumann et al. ${ }^{30}$, indicated that patients with signs of rigidity and bradykinesia had a higher risk of cognitive dysfunction than those with tremor symptoms, while
Wang et al. ${ }^{9}$ also found positive correlations between tremors and cognitive test scores.

Alesovski et al. ${ }^{31}$, monitored the clinical progression of PD patients separated into a dominant tremor group (Group 1) and a postural disturbances and gait instability group (Group 2) over four years. After this period they found that Group 2 exhibited a more progressive deterioration in cognition than Group 1, which had a tendency to maintain a stable cognition.

The present study identified a significant difference between the elderly and non-elderly groups in DLDD, SCOPA-COG total score (and the Executive Functions domain) and total MMSE score. Adhikari et al. ${ }^{10}$ reported that individuals aged over 60 with PD scored significantly lower on tasks that assessed memory and executive functions, while there was no difference between the groups in the MMSE. The reason for the absence of such a difference may be the small sample size, the fact that the majority of the sample was younger than 70 years, and the exclusion of patients with signs of dementia.

Dujardin et al. ${ }^{32}$ categorized the sample into five groups according to cognitive phenotypes. Group 1 (G1) was composed of individuals with PD and intact cognition, while Group 4 (G4) included those with PD and severe cognitive deficits, particularly in executive functions. These two groups differed significantly in relation to age, with G1 having a mean age of 61 years and G4 a mean age of 73 years, showing how age affects performance in executive function tests.

While studies exist in literature that associate cognition in PD with age, to the best of our knowledge there are few comparisons between groups of elderly and non-elderly with PD and none at all for the Brazilian population. In the present study the elderly had a higher percentage of cognitive impairment than the non-elderly. In the study by Isella et al. ${ }^{16}$, which used the SCOPA-COG, patients with PD and dementia were older and less educated than patients with PD who did not suffer cognitive impairment.

Levy et al. ${ }^{33}$ evaluated four groups of 180 individuals with $\mathrm{PD}$, separating them by age $(<72$ 
and $\geq 72$ ) and greater or lesser severity of the disease. The older/more severe group had a higher risk of dementia (RR: 9.7) than the younger group with less severe conditions. When the factor of severity of disease was eliminated, the $\geq 72$-year-old group was 1.6 times more likely to have dementia than those aged $<72$ years. These studies confirm the influence of aging as a risk factor for dementia in $\mathrm{PD}^{11}$.

The elderly in the present study were 3.32 times more likely to be categorized with cognitive impairment than the non-elderly, according to SCOPA-COG. In a two-year follow-up study, a 70 -year-old patient had a predicted risk of cognitive impairment of $13 \%$ within two years, while a 50 -yearold had a predicted risk of $5 \%$ over the same period ${ }^{34}$.

Cultural and educational differences should be considered when comparing data from Brazilian individuals with studies from Europe and the USA. Such comparison is necessary in the case of the present work, however, as to date it is the only study which compares the cognitive profile of Brazilian elderly and non-elderly individuals with PD.

\section{REFERENCES}

1. Pinheiro JLS, Barbosa MT. Doença de Parkinson e outros distúrbios do movimento em idosos. In: Freitas EV, Py L. Tratado de Geriatria e Gerontologia. 4. ed. Rio de Janeiro: Guanabara Koogan; 2016. p. 609-26.

2. Barbosa ER, Ferraz HB. Doença de Parkinson. In: Neto JPB, Takayanagui OM, orgs. Tratado de neurologia da Academia Brasileira de Neurologia. Rio de Janeiro: Elsevier; 2013. p.315-25.

3. Robbins TW, Cools R. Cognitive deficits in Parkinson's Disease: a cognitive neuroscience perspective. Mov Disord. 2014;29(5):597-607.

4. Rodrigues AV, Lemes LB, Rodrigues AS, Souza $\mathrm{RB}$, Santos SMS. Avaliação do sistema perceptual em idosos saudáveis e em idosos com Doença de Parkinson. Rev Neurociênc. 2014;22(2):189-94.

5. Litvan I, Goldman JG, Tröster AI, Schmand BA, Weintraub D, Petersen RC, et al. Diagnostic criteria for mild cognitive impairment in Parkinson's disease: Movement Disorder Society Task Force guidelines. Mov Disord. 2012;27(3):349-56.
Possible limitations of the present study include its sample size; the cross-sectional design, which does not allow the identification of causality; the noninclusion of a control group of elderly and non-elderly individuals without PD and the application of tests in the on-medication stage only. Future studies with a larger sample size should also focus on the longitudinal monitoring of possible differences in the cognitive status of elderly and non-elderly individuals with PD.

\section{CONCLUSION}

The findings of the present study indicate that being elderly and having Parkinson's disease and a work activity with a lower cognitive demand are factors that negatively affect cognition, and can increase the chances of progression to dementia. The presence of tremors, meanwhile, was seen as a possible protective factor for cognition. These results, combined with longitudinal studies, may provide support for the formulation of treatments of prevention and cognitive rehabilitation, taking into account the influence of the factor of age on the cognitive performance of patients with Parkinson's disease.

6. Emre M, Aarsland D, Brown R, Burn DJ, Duyckaerts C, Mizuno Y, et al. Clinical diagnostic criteria for dementia associated with Parkinson's disease. Mov Disord. 2007;22(12):1689-707.

7. Ding W, Ding LJ, Li FF, Han Y, Mu L. Neurodegeneration and cognition in Parkinson's disease: a review. Eur Rev Med Pharmacol Sci. 2015;19(12):2275-81.

8. Sartor J, Bettecken K, Bernhard FP, Hofmann M, Gladow T, Lindig T, et al. White matter changesrelated gait and executive function deficits: associations with age and Parkinson's Disease. Front Aging Neuroscience. 2017;9:1-9.

9. Wang I, Tang BS, Yan XX, Chen ZH, Xu Q, Liu ZH, et al. A neurophysiological profile in Parkinson's disease with mild cognitive impairment and dementia in China. J Clin Neurosci. 2015;22(6):981-5. 
10. Adhikari S, Basu J, Das SK, Misra AK. Effects of age, stage of disease, and educational level on cognitive dysfunction in non-demented idiopathic Parkinsonism: a preliminary report. Ind Psychiatry J. 2012;21(1):32-8.

11. Zhu K, Van Hilten JJ, Marinus J. Predictors of dementia in Parkinson's disease: findings from a 5 -year prospective study using the SCOPA-COG. Parkinsonism Relat Disord. 2014;20(9):980-5.

12. Carod-Artal FJ, Martínez-Martin P, Kummer W, Ribeiro LS. Psychometric attributes of the SCOPACOG Brazilian version. Mov Disord. 2008;23(1):81-7.

13. Martins NIM, Caldas PR, Cabral ED, Lins CCSA, Coriolano MGWS. Instrumentos de avaliação cognitiva utilizados nos últimos 5 anos em idosos Brasileiros. Ciênc Saúde Colet [Internet]. 2017 [acesso em 02 fev. 2018]. Disponível em: http://www. cienciaesaudecoletiva.com.br/artigos/instrumentosde-avaliacao-cognitiva-utilizados-nos-ultimos-5-anosem-idosos-brasileiros/16454?id=16454

14. Marinus J, Visser M, Verwey NA, Verhey FR, Middelkoop HA, Stiggelbout AM, et al. Assessment of cognition in Parkinson's disease. Neurology. 2003;61(9):1222-8.

15. Verbaan D, Jeukens-Visser M, Van Laar T, van Rooden SM, Van Zwet EW, Marinus J, et al. SCOPAcognition cutoff value for detection of Parkinson's disease dementia. Mov Disord. 2011;26:1881-6.

16. Isella V, Mapelli C, Morielli N, Siri C, De Gaspari D, Pezzoli G, et al. Diagnosis of possible mild cognitive impairment in Parkinson's Disease: Validity of the SCOPA-Cog. Parkinsonism Relat Disord. 2013;19:1160-3.

17. Folstein MF, Folstein SE, Mchugh PR. Mini-Mental State: a practical method for grading the cognitive state of patients for the clinician. J Psychiatric Res. 1975;12:189-98.

18. Brucki SMD, Nitrini R, Caramelli P, Bertolucci PHF, Okamoto IH. Sugestões para o uso do mini-exame do estado mental no Brasil. Arqu Neuropsiquiatr. 2003;61(3B):777-81.

19. Vitiello APP, Ciríaco JGM, Takahashi DY, Nitrini R, Caramelli P. Avaliação cognitiva breve de pacientes atendidos em ambulatório de neurologia geral. Arq Neuropsiquiatr. 2007;65(2-A):299-303.

20. Associação Brasileira de Empresas de Pesquisa. Critério Brasil de Classificação Econômica 2016 [Internet]. São Paulo: ABEP; [201?] [acesso 12 fev 2017]. Disponível em: http://www.abep.org/criterio-brasil

21. Tomlinson CL, Stowe R, Patel S, Rick C, Gray R, Clarke CE. Systematic review of Levodopa dose equivalency reporting in Parkinson's disease. Mov Disord. 2010;25(15):2649-53.
22. Bucki PO, Wilson RE, Seeberger LC, Conner JB, Castelli-Haley J. Examination of the UPDRS Bradykinesia Subscale: equivalence, reliability and validity. J Park Dis. 2011;1(3):253-8.

23. Murakami H, Owan Y, Mori Y, Fujita K, Futamura A, Sugimoto A, et al. Correlation between motor and cognitive functions in the progressive course of Parkinson's disease. Neurol Clin Neurosci. 2013;1:172-6.

24. Yesavage JA, Brink TL, Rose TL, Lum O, Huang $\mathrm{V}$, Adey M, et al. Development and validation of a geriatric depression screening scale: a preliminary report. J Psychiatr Res. 1983;17(1):37-49.

25. Bohnen JLB, Müller MLTM, Haugen J, Bohnen N. Mentally stimulating activities associate with better cognitive performance in Parkinson disease. J Neural Transm. 2017;124(10):1205-12.

26. Silveira MM, Portuguez MW. Análise da qualidade de vida e prevalência de declínio cognitivo, ansiedade e sintomas depressivos em idosos. Estud Psicol (Campinas). 2017;34(2):261-8.

27. Pool LR, Weuve J, Wilson RS, Bültmann U, Evans DA, Mendes de Leon CF. Occupational cognitive requirements and late-life cognitive aging. Neurology. 2016;86(15):1386-92.

28. Smart EL, Gow AJ, Deary IJ. Occupational complexity and lifetime cognitive abilities. Neurology. 2014;83:2285-91.

29. Stern Y. Cognitive reserve and Alzheimer disease. Alzheimer Dis Assoc Disord. 2006;20(2):112-7.

30. Baumann CR, Held U, Valko PO, Wienecke M, Waldvogel D. Body side and predominant motor features at the Onset of Parkinson's Disease Are Linked to Motor and Nonmotor Progression. Mov Disord. 2014;29(2):207-13.

31. Alesovski D, Miljkovic D, Bravi D, Antonini A. Disease progression in Parkinson subtypes: the PPMI dataset. Neurol Sci. 2018;39(11):1971-6.

32. Dujardin K, Moonen AJH, Behal H, Defebvre L, Duhamel A, Duits AA, et al. Cognitive disorders in Parkinson's disease: confirmation of a spectrum of severity. Parkinsonism Relat Disord. 2015;21(11):1299-305.

33. Levy G, Schupf N, Tang M, Cote LJ, Louis ED, Mejia $\mathrm{H}$, et al. Combined effect of age and severity on the risk of dementia in Parkinson's Disease. Ann Neurol. 2002;51(6):722-9.

34. Schrag A, Siddiqui UF, Anastasiou Z, Weintraub $\mathrm{D}$, Schott JM. Clinical variables and biomarkers in prediction of cognitive impairment in patients with newly diagnosed Parkinson's disease: a cohort study. Lancet Neurol. 2017;16(1):66-75. 